\title{
Retroperitoneal Sarcoma
}

National Cancer Institute

\section{Source}

National Cancer Institute. Retroperitoneal Sarcoma. NCI Thesaurus. Code C4832.

A sarcoma that occurs in the retroperitoneal region. 